\title{
Structural Model of Strengths and Virtues on Basis of Positive Psychology*
}

\author{
Zhan Qisheng, Liu Yuanyuan \\ Tianjin University, Tianjin, China
}

\author{
Su Huili \\ Nankai University, Tianjin, China
}

\author{
Zhang Kuo, Feng Chuande \\ Tianjin University, Tianjin, China
}

\begin{abstract}
Positive psychology is established by Seligman in the 1990s. It is related to a series of new concepts such as positive virtues or strengths. A variety of influential factors in positive psychology have been explored in this article. Ninety-six positive strengths and virtues have been confirmed on the basis of a survey which involves 7,059 participants. Subsequently, a structural equational model with 13 latent variables has been established according to various personality theories and results of above survey. Moreover, this model has been confirmed through confirmatory factor analysis as a nice one with good absolute fit indices and good comparative fit indices.
\end{abstract}

Keywords: positive psychology, strengths and virtues, fit indices, structural equational model

\section{Introduction}

Mental health service in the world has been undergoing a huge change from focusing upon psychological problems to stressing on positive traits. Mental health practitioners, clinical psychologists, psychotherapists, and psychological counselors all put emphasis on the symptoms of human mental disorders. Positive psychology, founded in the 1990s, has put forward a new perspective of how to cope with psychological problems and concentrate upon human positive traits. Thus, a tremendous change has occurred to psychological sciences and human beings' life because of positive psychology. Above all, American psychologist Seligman and Csikszentmihalyi (2000) formally put forward the concept of positive psychology. Three main themes of positive psychology are positive subjective experience, positive personal traits, and positive environment. Seligman (1998) suggested that psychology should recover the two other missions of facilitating human good life and nurturing talent besides treating mental diseases. Building human strengths is one of the most critical goals of positive psychology.

However, first of all, we must explore the structure of human positive traits so as to reach the above goals. Many problems such as quantity, quality, and classification of strengths and virtues need to be solved. Seligman (1999) has called for a taxonomy of the strengths and virtues that promote resilience and

\footnotetext{
*Acknowledgements: This study is supported by a grant from the Humanities and Social Sciences Research Program in Tianjin Municipal Education Commission (2011FDY04); it is also one part of Tianjin Education Science "Twelfth Five-year" Planning Issue (HE4103).

Zhan Qisheng, Ph.D., associate professor, Director of Institute of Psychology, Tianjin University.

Liu Yuanyuan, Master student, Institute of Psychology, Tianjin University.

Su Huili, Doctoral student, Department of Social Psychology, Nankai University.

Zhang Kuo, Master student, Institute of Psychology, Tianjin University.

Feng Chuande, Master student, Institute of Psychology, Tianjin University.
} 
responsibility in individuals. Meanwhile, family social scientists and family therapists have developed substantive bodies of scholarly and applied literature in such related areas as family strength frameworks (Stinnett, Stinnett, DeFrain, \& DeFrain, 1997; Sandage \& Hill, 2001).

As a matter of fact, positive psychology can be traced back to Maslow's humanistic theory and positive psychotherapy founded by German psychologist Peseschkian (1987). Peseschkian (1987) gave us a new analytical pathway to observe human dynamic strengths and virtues. However, positive psychology is different from humanistic psychology (Bohart \& Greening, 2001). Fredrickson (2001) paid special attention to the dimension of positive emotions. Foster and Lloyd (2007) pointed out some concrete strategies of identifying and applying personal strengths and virtues. Wood and Tarrier (2010) believed that mental disorders can be treated through promoting the positive characteristics which include gratitude, flexibility, and positive emotions. In addition, people's stressors can be dealt with by means of positive imagination (Davis \& Asliturk, 2011). Wong (2011) regarded meaning, virtue, resilience, and well-being as four basic elements of beautiful life. On the whole, the research on systems of positive traits of positive psychology is still scarce (Gable \& Haidt, 2005). Therefore, this article will explore the structural model of positive traits.

\section{Methods}

\section{Sample and Participants}

Seven thousand and fifty-nine college students were surveyed. They come from 12 universities and colleges in Tianjin city, China, which involve Tianjin University, Nankai University, Tianjin Normal University, Tianjin Medical University, and so on.

\section{Sex}

Among the total participants, there are 2,938 male students, accounting for $41.6 \%$, and 3,744 female students, accounting for $53.1 \%$. Besides, 377 (accounting for 5.3\%) other college students did not answer the question of sex.

\section{Measures}

To use the open-ended questions as the items of survey method. Every respondent has to answer only two questions: One is "What is my most important strength?"; and the other one is "What is my biggest weakness?".

\section{Statistical Software}

All questionnaire data are analyzed by SPSS 16.0 (Statistical Product and Service Solutions) and Lisrel 8.51 (Linear Structural Relations).

\section{Results and Discussion}

In this survey, 7,059 participants answered the questionnaire. Two thousand and sixty-three participants' answers are inexact, and 4,996 questionnaires are valid. The results are listed in Table 1.

On the basis of the theories of Cattell's Sixteen Personality Factors Questionnaire, Eysenck Personality Questionnaire, the Big Five Personality Traits Model, and other theories related to characteristics of cognition, emotion, and behavior in psychology, the 96 strengths and virtues can be divided into 13 latent variables, L1-L13. Each latent variable is comprised of correspondent items: 
Table 1

College Students' Strengths and Virtues

\begin{tabular}{|c|c|c|}
\hline No. & Strengths and virtues & Freq. \\
\hline V1 & Self-confidence & 982 \\
\hline $\mathrm{V} 2$ & Optimistic & 291 \\
\hline $\mathrm{V} 3$ & Conscientious & 235 \\
\hline V4 & Intelligent & 208 \\
\hline V5 & Diligent & 204 \\
\hline V6 & Strong sociability & 187 \\
\hline V7 & Kindness & 157 \\
\hline V8 & Understanding oneself & 133 \\
\hline V9 & Open-minded & 133 \\
\hline $\mathrm{V} 10$ & Sincerity & 112 \\
\hline V11 & Introspection & 98 \\
\hline $\mathrm{V} 12$ & Perseverance & 94 \\
\hline V13 & Good interpersonal relationship & 92 \\
\hline V14 & Strong Self-control & 83 \\
\hline V15 & Enthusiastic & 79 \\
\hline V16 & Unremitting & 66 \\
\hline V17 & Easy-going & 62 \\
\hline $\mathrm{V} 18$ & Honest & 62 \\
\hline V19 & Patient & 59 \\
\hline V20 & Talkative & 57 \\
\hline V21 & Strong & 55 \\
\hline V22 & Calmness & 53 \\
\hline V23 & Motivated & 52 \\
\hline V24 & Persistent & 50 \\
\hline V25 & Psychological diathesis & 46 \\
\hline V26 & Steady & 45 \\
\hline V27 & Gentle & 45 \\
\hline V28 & Good-looking & 41 \\
\hline V29 & Studious & 38 \\
\hline $\mathrm{V} 30$ & Rational & 37 \\
\hline V31 & Good comprehensive ability & 36 \\
\hline V32 & Good grades & 36 \\
\hline V33 & Love sports & 36 \\
\hline V34 & Good at thinking & 35 \\
\hline V35 & Good learning capacity & 34 \\
\hline V36 & With broad interests & 34 \\
\hline V37 & Goal-oriented & 34 \\
\hline $\mathrm{V} 38$ & Considerate & 33 \\
\hline V39 & Strong sense of responsibility & 33 \\
\hline V40 & Have affinity & 33 \\
\hline V41 & Logical thinking & 30 \\
\hline V42 & Down-to-earth & 30 \\
\hline V43 & Real & 29 \\
\hline V44 & Helpful & 29 \\
\hline V45 & Modest & 28 \\
\hline V46 & Tolerant & 28 \\
\hline V47 & Quick-wittedness & 28 \\
\hline V48 & Strong adaptability & 28 \\
\hline V49 & In good health & 25 \\
\hline
\end{tabular}

(Table 1 to be continued)

\begin{tabular}{|c|c|c|}
\hline No. & Strengths and virtues & Freq. \\
\hline V50 & Good endurance & 25 \\
\hline V51 & Good memory & 24 \\
\hline V52 & Careful & 22 \\
\hline V53 & Idealistic & 22 \\
\hline V54 & Ambitious & 21 \\
\hline V55 & Silent & 20 \\
\hline V56 & Resilience & 20 \\
\hline V57 & Good sleep & 18 \\
\hline V58 & Good receptivity & 18 \\
\hline V59 & Practical ability & 17 \\
\hline V60 & Whole-hearted & 17 \\
\hline V61 & Thoughtful & 17 \\
\hline V62 & Self-improvement & 16 \\
\hline V63 & Efficient & 15 \\
\hline V64 & Risible & 15 \\
\hline V65 & In good faith & 14 \\
\hline V66 & Independent & 13 \\
\hline V67 & Brave & 13 \\
\hline V68 & In good figure & 12 \\
\hline V69 & Integrity & 12 \\
\hline V70 & Competent & 12 \\
\hline V71 & Humorous & 11 \\
\hline V72 & Good expressive power & 11 \\
\hline V73 & Quiet & 11 \\
\hline V74 & Good self-regulation ability & 10 \\
\hline V75 & Obedient & 10 \\
\hline V76 & Organized and planed & 9 \\
\hline V77 & Meek & 9 \\
\hline V78 & Learned & 9 \\
\hline V79 & Curiosity & 8 \\
\hline V80 & Strong character & 8 \\
\hline V81 & Lovable & 8 \\
\hline V82 & Passionate & 7 \\
\hline V83 & Self-supporting & 7 \\
\hline V84 & Imaginative & 7 \\
\hline V85 & Active & 7 \\
\hline V86 & Mature & 6 \\
\hline V87 & Sympathetic & 5 \\
\hline V88 & Innovation ability & 5 \\
\hline V89 & Principled & 5 \\
\hline V90 & Pure & 5 \\
\hline V91 & Have certain specialties & 5 \\
\hline V92 & High emotional quotient & 4 \\
\hline V93 & Leadership ability & 4 \\
\hline V94 & Initiative & 3 \\
\hline V95 & Assertive & 3 \\
\hline \multirow[t]{2}{*}{ V96 } & Generous & 1 \\
\hline & Total & 4,996 \\
\hline
\end{tabular}


L1 (goal and confidence): V1, V8, V25, V37, V53, V62, V70, V76, V78

L2 (social ability): V6, V13, V15, V20, V40, V44, V72, V92, V94

L3 (conscientiousness): V3, V5, V11, V29, V39, V52, V60, V89

L4 (optimism): V9, V55, V64, V71, V73, V79

L5 (physical characteristic): V28, V49, V57, V68, V81

L6 (intellectual ability): V31, V35, V51, V58, V59, V88, V93

L7 (willpower): V12, V14, V16, V19, V21, V24, V48, V50, V56, V74

L8 (authenticity): V10, V18, V26, V42, V43, V45, V65, V69

L9 (traits of thinking): V4, V32, V34, V41, V47, V63, V84

L10 (autonomy): V61, V66, V75, V80, V83, V95

L11 (considerateness): V7, V17, V27, V38, V46, V87, V96

L12 (aggressiveness): V2, V23, V33, V36, V54, V82, V85, V91

L13 (rationality): V22, V30, V67, V77, V86, V90

\section{Psychometrics}

After the above-mentioned structural equational model had been established, 193 undergraduates and 126 postgraduates were invited to participate in a self-reported questionnaire with 96 strengths and virtues. Participants should rate the 96 strengths one by one from 1 to 7 , in which 1 indicates "The most inappropriate to him/her", and 7 indicates "The most appropriate to him/her".

After inputing these data and establishing the structural equational model, by running the program with lisrel 8.51, the LISREL estimates (Maximum Likelihood) could be gotten. Afterwards, the model should be modified according to Modification Indices for LAMBDA-X matrix, Completely Standardized Solution $(<0.50)$ and their meanings. For this reason, some dissatisfactory variables have to be deleted or transferred in the following.

In latent V1: delete five variables from "goal and confidence (L1)", which are V8 (Understanding oneself), V25 (Psychological diathesis), V62 (Self-improvement), V70 (Competent), and V78(Learned).

In latent V2: delete four variables from "social ability (L2)", which are V13 (Good interpersonal relationship), V20 (Talkative), V40 (Have affinity), V44 (Helpful), and transfer V15 (Enthusiastic) from "social ability (L2)" to "optimism (L4)".

In latent V3: delete two variables from "conscientiousness (L3)", which are V11 (Introspection) and V89 (Principled).

In latent V4: delete two variables from "optimism (L4)", which are V55 (Silent) and V73 (Quiet).

In latent V5: delete three variables from "physical characteristic (L5)", which are V49 (In good health), V57 (Good sleep), and V81(Lovable).

In latent V6: transfer only one variable from "intellectual ability (L6)" to "social ability (L2)", which is V93 (Leadership ability).

In latent V7: delete five variables from "willpower (L7)", which are V19 (Patient), V21 (Strong), V48 (Strong adaptability), V50 (Good endurance), and V74 (Good self-regulation ability).

In latent V8: delete five variables from "authenticity (L8)", which are V10 (Sincerity), V26 (Steady), V42 (Down-to-earth), V43 (Real), and V69 (Integrity).

In latent V9: delete only one variable from "traits of thinking (L9)", which is V32 (Good grades). 
In latent V10: delete three variables from "autonomous (L10)", which are V66 (Independent), V75 (Obedient), and V80 (Strong character).

In latent V11: delete two variables from "considerateness (L11)", which are V7 (Kindness) and V87 (Sympathetic).

In latent V12: delete five variables from "aggressiveness (L12)", which are V2 (Optimistic), V33 (Love sports), V82 (Passionate), V85 (Active), and V91 (Have certain specialties).

In latent V13: delete three variables from "rationality (L13)", which are V67 (Brave), V77 (Meek), and V90 (Pure).

Other 96 satisfactory variables are composed of New Structural Equational Model in LAMBDA-X matrix. The LAMBDA-X matrix can be tabulated in Table 2.

Table 2

Factor Load of Different Items in Their Corresponding Latent Variables

\begin{tabular}{|c|c|c|c|c|c|c|c|c|c|c|c|c|c|c|}
\hline No. & Item & $\mathrm{L} 1$ & L2 & L3 & L4 & L5 & L6 & L7 & L8 & L9 & L10 & L11 & $\mathrm{L} 12$ & $\mathrm{~L} 13$ \\
\hline V37 & goal-oriented & 0.66 & & & & & & & & & & & & \\
\hline V53 & idealistic & 0.63 & & & & & & & & & & & & \\
\hline V1 & self-confidence & 0.51 & & & & & & & & & & & & \\
\hline V76 & organized and planned & 0.59 & & & & & & & & & & & & \\
\hline V72 & good expressive power & & 0.67 & & & & & & & & & & & \\
\hline V92 & high emotional quotient & & 0.55 & & & & & & & & & & & \\
\hline V15 & enthusiastic & & & & 0.75 & & & & & & & & & \\
\hline V6 & strong sociability & & 0.54 & & & & & & & & & & & \\
\hline V94 & initiative & & 0.75 & & & & & & & & & & & \\
\hline V29 & studious & & & 0.62 & & & & & & & & & & \\
\hline V5 & diligent & & & 0.66 & & & & & & & & & & \\
\hline V3 & conscientious & & & 0.59 & & & & & & & & & & \\
\hline V52 & careful & & & 0.55 & & & & & & & & & & \\
\hline V39 & strong sense of responsibility & & & 0.53 & & & & & & & & & & \\
\hline V60 & whole-hearted & & & 0.56 & & & & & & & & & & \\
\hline V64 & risible & & & & 0.52 & & & & & & & & & \\
\hline V9 & open-minded & & & & 0.69 & & & & & & & & & \\
\hline V71 & humorous & & & & 0.52 & & & & & & & & & \\
\hline V79 & curiosity & & & & 0.55 & & & & & & & & & \\
\hline V68 & in good figure & & & & & 0.59 & & & & & & & & \\
\hline V28 & good-looking & & & & & 0.75 & & & & & & & & \\
\hline V88 & innovation ability & & & & & & 0.68 & & & & & & & \\
\hline V59 & practical ability & & & & & & 0.52 & & & & & & & \\
\hline V51 & good memory & & & & & & 0.62 & & & & & & & \\
\hline V58 & good receptivity & & & & & & 0.51 & & & & & & & \\
\hline V31 & good comprehensive ability & & & & & & 0.63 & & & & & & & \\
\hline V35 & good learning capacity & & & & & & 0.74 & & & & & & & \\
\hline V93 & Leadership ability & & 0.72 & & & & & & & & & & & \\
\hline V16 & unremitting & & & & & & & 0.80 & & & & & & \\
\hline V56 & resilience & & & & & & & 0.58 & & & & & & \\
\hline V12 & perseverance & & & & & & & 0.78 & & & & & & \\
\hline
\end{tabular}


(Table 2 to be continued)

\begin{tabular}{|c|c|c|c|c|c|c|c|c|c|c|c|c|c|c|}
\hline No. & Item & L1 & $\mathrm{L} 2$ & L3 & L4 & L5 & L6 & L7 & L8 & L9 & L10 & L11 & L12 & L13 \\
\hline V24 & persistent & & & & & & & 0.60 & & & & & & \\
\hline V14 & strong self-control & & & & & & & 0.72 & & & & & & \\
\hline V18 & honest & & & & & & & & 0.62 & & & & & \\
\hline V65 & in good faith & & & & & & & & 0.55 & & & & & \\
\hline V45 & modest & & & & & & & & 0.54 & & & & & \\
\hline V4 & intelligent & & & & & & & & & 0.56 & & & & \\
\hline V34 & good at thinking & & & & & & & & & 0.65 & & & & \\
\hline V47 & quick-wittedness & & & & & & & & & 0.71 & & & & \\
\hline V84 & imaginative & & & & & & & & & 0.51 & & & & \\
\hline V63 & efficient & & & & & & & & & 0.62 & & & & \\
\hline V41 & logical thinking & & & & & & & & & 0.54 & & & & \\
\hline V61 & thoughtful & & & & & & & & & & 0.68 & & & \\
\hline V95 & assertive & & & & & & & & & & 0.78 & & & \\
\hline V83 & self-supporting & & & & & & & & & & 0.58 & & & \\
\hline V96 & generous & & & & & & & & & & & 0.50 & & \\
\hline V46 & tolerant & & & & & & & & & & & 0.70 & & \\
\hline V27 & gentle & & & & & & & & & & & 0.68 & & \\
\hline V38 & considerate & & & & & & & & & & & 0.53 & & \\
\hline V17 & easy-going & & & & & & & & & & & 0.59 & & \\
\hline V23 & motivated & & & & & & & & & & & & 0.62 & \\
\hline V54 & ambitious & & & & & & & & & & & & 0.66 & \\
\hline V36 & with broad interests & & & & & & & & & & & & 0.57 & \\
\hline V22 & calmness & & & & & & & & & & & & & 0.76 \\
\hline V86 & mature & & & & & & & & & & & & & 0.58 \\
\hline V30 & rational & & & & & & & & & & & & & 0.63 \\
\hline
\end{tabular}

In addition, the correlation coefficients between thirteen Latent Variables are presented in PHI matrix. The results can be tabulated in Table 3 .

Table 3

Correlation Coefficients Between Latent Variables

\begin{tabular}{|c|c|c|c|c|c|c|c|c|c|c|c|c|c|}
\hline Latent variable & L1 & $\mathrm{L} 2$ & L3 & L4 & L5 & L6 & L7 & L8 & L9 & $\mathrm{L} 10$ & $\mathrm{~L} 11$ & $\mathrm{~L} 12$ & L13 \\
\hline 1. goal and confidence & 1.00 & & & & & & & & & & & & \\
\hline 2. social ability & 0.80 & 1.00 & & & & & & & & & & & \\
\hline 3. conscientiousness & 0.78 & 0.59 & 1.00 & & & & & & & & & & \\
\hline 4. optimism & 0.49 & 0.66 & 0.29 & 1.00 & & & & & & & & & \\
\hline 5. physical characteristic & 0.57 & 0.46 & 0.41 & 0.32 & 1.00 & & & & & & & & \\
\hline 6. intellectual ability & 0.73 & 0.72 & 0.56 & 0.64 & 0.54 & 1.00 & & & & & & & \\
\hline 7. willpower & 0.79 & 0.46 & 0.87 & 0.26 & 0.40 & 0.53 & 1.00 & & & & & & \\
\hline 8. authenticity & 0.46 & 0.22 & 0.74 & 0.32 & 0.22 & 0.36 & 0.47 & 1.00 & & & & & \\
\hline 9. traits of thinking & 0.77 & 0.72 & 0.57 & 0.58 & 0.57 & 0.99 & 0.59 & 0.32 & 1.00 & & & & \\
\hline 10. autonomy & 0.86 & 0.85 & 0.59 & 0.43 & 0.38 & 0.70 & 0.55 & 0.25 & 0.76 & 1.00 & & & \\
\hline 11. considerateness & 0.43 & 0.43 & 0.48 & 0.65 & 0.32 & 0.49 & 0.32 & 0.71 & 0.48 & 0.76 & 1.00 & & \\
\hline 12. aggressiveness & 0.79 & 0.86 & 0.50 & 0.87 & 0.46 & 0.78 & 0.44 & 0.47 & 0.80 & 0.80 & 0.62 & 1.00 & \\
\hline 13. rationality & 0.67 & 0.56 & 0.60 & 0.28 & 0.52 & 0.71 & 0.62 & 0.39 & 0.65 & 0.65 & 0.54 & 0.45 & 1.00 \\
\hline
\end{tabular}

Note. All $t$-values of above correlation coefficients are larger than $2.00(t \geq 2.00, p<0.05)$. 
Finally, the absolute model fit indices and the comparative model fit indices can be showed in Table 4.

The results of Table 4 show that in this model, RMSEA (Root Mean Square Error of Approximation) is less than 0.08, and NNFI (Non-Normed Fit Index), CFI (Comparative Fit Index), and IFI (Incremental Fit Index) are all greater than 0.90 , which indicate that this model has satisfactory fit indices.

Table 4

Various Fit Indices of Strengths and Virtues Model

\begin{tabular}{cccccc}
\hline$\chi^{2}$ & $d f$ & RMSEA & NNFI & CFI & IFI \\
\hline 1660.42 & 1406 & 0.035 & 0.91 & 0.92 & 0.92 \\
\hline
\end{tabular}

Notes. RMSEA: Root Mean Square Error of Approximation; NNFI: Non-Normed Fit Index; CFI: Comparative Fit Index; IFI: Incremental Fit Index.

According to the results of Tables 2, 3, and 4, this article confirmed a good new model related to strengths and virtues from the perspective of positive psychology. This model shows that college students' strengths and virtues can be identified as 13 important factors which are goal and confidence, social ability, conscientiousness, optimism, physical characteristic, intellectual ability, willpower, authenticity, traits of thinking, autonomy, considerateness, aggressiveness, and rationality.

As a college student, he/she can develop his/her positive personality traits in the light of this model. First of all, "setting a goal and boosting self-confidence" is the most critical strength for each college student. It is also one of the most important tasks to improve college students' sociability, to develop intellectual ability, to cultivate the optimistic attitudes, to train the traits of thinking, and so on. In a word, future study had better convert to the direction towards how to use this model as a valid tool for college students' growth.

Meanwhile, several limitations in this study deserve comment. Almost $29 \%$ of survey respondents described their strengths and virtues in inexact words. Furthermore, the interpretations to some similar positive personality traits are often confused. In addition, the size and structure of the sample still need to be standardized or optimized.

\section{Conclusions}

In conclusion, this paper established a new model of college students' strengths and virtues by means of the data of large sample, several classic and traditional personality theories, and scientific statistical methods. This model can be confirmed to have good fit indices, thus it belongs to a valid and valuable model related to positive personality traits.

\section{References}

Bohart, A. C., \& Greening, T. (2001). Humanistic psychology and positive psychology. American Psychologist, 56(1), 81-82.

Davis, C. G., \& Asliturk, E. (2011). Toward a positive psychology of coping with anticipated events. Canadian Psychology, 52(2), 101-110.

Foster, S. L., \& Lloyd, P. J. (2007). Positive psychology principles applied to consulting psychology at the individual and group level. Consulting Psychology Journal: Practice and Research, 59(1), 30-40.

Fredrickson, B. L. (2001). The role of positive emotions in positive psychology: The broaden-and-build theory of positive emotions. American Psychologist, 56(3), 218-226.

Gable, S. L., \& Haidt, J. (2005). What (and why) is positive psychology? Review of General Psychology, 9(2), 103-110.

Peseschkian, N. (1987) Positive psychotherapy: Theory and practice of a new method. Berlin, New York: Springer-Verlag.

Sandage, S. J., \& Hill, P. C. (2001). The virtues of positive psychology: The rapprochement and challenges of an affirmative postmodern perspective. Journal for the Theory of Social Behaviour, 31(3), 241-260. 
Seligman, M. E. P. (1998). Building human strength: Psychology's forgotten mission. APA Monitor, January 2.

Seligman, M. E. P. (1998). What is the "good life"? APA Monitor, October 2.

Seligman, M. E. P. (1999). The president's address. American Psychologist, 54, 559-562.

Seligman, M. E. P., \& Csikszentmihalyi, M. (2000). Positive psychology: An introduction. American Psychologist, 55(1), 5-14.

Stinnett, N., Stinnett, N., DeFrain, J., \& DeFrain, N. (1997). Good families. New York: Doubleday.

Wong, P. T. P. (2011). Positive psychology 2.0: Towards a balanced interactive model of the good life. Canadian Psychology, 52(2), 69-81.

Wood, A. M., \& Tarrier, N. (2010). Positive clinical psychology: A new vision and strategy for integrated research and practice.

Clinical Psychology Review, 30(7), 819-829. 